\title{
AS EXPERIÊNCIAS E O PROTAGONISMO DAS CRIANÇAS NAS SALAS TEMÁTICAS DE UMA EMEI DE RONDONÓPOLIS/MT*
}

\author{
Roseni da Rosa (SEMED/ROO) \\ Sandra Celso de Camargo (SEMED/ROO)
}

\begin{abstract}
A criança é feita de cem
A criança tem cem mãos, cem pensamentos, cem modos de pensar, de jogar e de falar.

Cem, sempre cem modos de escutar as maravilhas de amar.

Cem alegrias para cantar e compreender.

Cem mundos para descobrir. Cem mundos para inventar.

Cem mundos para sonhar.

A criança tem cem linguagens (e depois, cem, cem, cem), mas roubaram-lhe noventa e nove.

A escola e a cultura separam-lhe a cabeça do corpo.

Dizem-lhe: de pensar sem as mãos, de fazer sem a cabeça, de escutar e de não falar, de compreender sem alegrias, de amar e maravilharse só na Páscoa e no Natal.

Dizem-Ihe: de descobrir o mundo que já existe e, de cem, roubaramIhe noventa e nove.

Dizem-lhe: que o jogo e o trabalho, a realidade e a fantasia, a ciência e a imaginação, o céu e a terra, a razão e o sonho, são coisas que não estão juntas.

Dizem-Ihe: que as cem não existem. A criança diz: ao contrário, as cem existem.
\end{abstract}

(MALAGUZZI, 1999, p. 60)

\section{O Início de uma Trajetória}

A ideia da implantação de sistema das Salas Temáticas surgiu no mês de agosto do ano de 2017, em uma Escola Municipal de Educação Infantil (EMEI), que atende a crianças de 4 (quatro) e 5 (cinco) anos do município de Rondonópolis/MT devido à necessidade de mudança da Instituição, uma vez que o prédio passaria por reforma. Nesse contexto, tivemos que encontrar um lugar/espaço para que pudéssemos continuar com o atendi-

"DOI - 10.29388/978-65-86678-68-0-0-f.167-178 
mento às crianças. Contudo, o local encontrado não dispunha de salas suficientes para atender as seis turmas num mesmo período. Nesse sentido, o espaço foi organizado por Salas Temáticas, com os seguintes temas: Artes, Literatura, Jogos e Brinquedoteca. Assim, fizemos um cronograma em que a cada dia duas turmas dividiriam a mesma Sala, num sistema de rodízio.

No ano de 2018, de volta à sede da Escola, continuamos com o projeto, porém como ainda não haviam finalizado a reforma e não tinham entregado todas as salas, continuamos com o cronograma em que duas turmas utilizavam a mesma Sala durante o mesmo período.

No ano de 2019, com a reforma concluída, avaliamos que mesmo sem ter desenvolvido o projeto da forma como desejávamos ${ }^{1}$, seria pertinente e produtivo manter as Salas Temáticas. Então, no decorrer deste ano, o projeto foi aprimorado quanto à sua finalidade e importância para o desenvolvimento das crianças, com o intuito de alcançarmos, efetivamente, o objetivo proposto, que consiste em proporcionar melhor organização dos espaços, tempos e materiais, para que as crianças possam vivenciar experiências significativas, através das interações e brincadeiras, sendo protagonistas da sua construção de conhecimentos, vivenciando, por meio das situações de aprendizagem apresentadas, a infância como tempo de vida, sem serem homogeneizadas e/ou estereotipadas por uma visão adultocêntrica.

A EMEI é a pioneira e a única até então, na cidade de Rondonópolis/MT, com atendimento nessa perspectiva de Salas Temáticas para a Educação Infantil. A Escola é organizada, atualmente, em seis Salas para todas as turmas: Sala de Jogos, Sala de Ciências e Tecnologia, Sala de Literatura, Sala de Música e Movimento, Sala do Ateliê e Sala da Brinquedoteca. Esta organização proporciona maiores oportunidades para que as crianças construam conhecimentos significativos em relação aos patrimônios cultural, artístico, ambiental, científico e tecnológico.

A denominação de cada Sala marca a intencionalidade pedagógica da instituição. Ao planejar para uma Sala Temática, o (a) professor (a) tem

\footnotetext{
${ }^{1}$ No início do ano de 2019, a Equipe Gestora, Conselho Deliberativo de Pais, Professores (as) e demais funcionários, se reuniram na Semana Pedagógica para discutirem e avaliarem o Projeto Político Pedagógico (PPP), buscando traçar metas para o novo ano letivo. Com isso, um dos pontos de análise foi o Projeto Salas Temáticas que, no segundo semestre do ano letivo de 2017, teve sua semente plantada no PPP da EMEI e, por meio da avaliação dos seus pontos fortes e suas fragilidades, observamos que neste ano, com o prédio terminado, 0 Projeto poderia ser efetivado a partir da prática pedagógica, por meio de um planejamento sistemático que levasse em consideração essa nova organização dos espaços, tempos, materiais e práticas.
} 
em mãos um arcabouço de possibilidades de linguagem para serem experienciadas pelas crianças, uma vez que um espaço assim organizado favorece que as crianças protagonizem as suas experiências.

Com esta organização, todos os materiais, espaços e tempos precisam ser pensados e planejados, inclusive os espaços externos, os quais são ampliações das Salas Temáticas e devem ser organizados para promoverem experiências nas diversas linguagens, assim como nas Salas. Nesse sentido, elaboramos um cronograma onde cada dia o (a) professor (a) e a sua turma ficam em uma Sala.

As crianças se mostram interessadas pelas Salas Temáticas, sabem a sequência do rodízio e assim se unem para preservar o patrimônio escolar que é dividido por todos da Instituição, desenvolvendo a empatia e a responsabilidade social desde cedo, além do estímulo ao senso de organização. Essa dinâmica das Salas contribuiu também para a aquisição dos materiais pedagógicos. Nas antigas salas de referências, cada sala deveria compor colas, tesouras, jogos, entre outros materiais para atender à demanda das turmas. Com as Salas Temáticas, esses materiais se concentram em salas específicas, contribuindo assim para que os recursos sejam melhor redimensionados e para que tenhamos maior variedade de materiais e possibilidades.

\section{O caminho que se faz no caminhar}

A rotina, pensada como uma organização do cotidiano, é um aspecto importante para a criança, traz segurança e estabilidade, porém, deve ser flexível e contextualizada, considerando os desejos e necessidades das crianças.

A organização dos tempos, espaços e materiais nas instituições de Educação Infantil não é um anseio recente. Assim, por meio das Salas Temáticas a EMEl aceitou o desafio de planejar uma organização de espaços, tempos e materiais que supere a rotina "rotineira", a qual aprisiona, muitas vezes, as crianças numa perspectiva adultocêntrica.

Este espaço é pensado de forma a possibilitar experiências, investigações, relações e desafios onde as crianças se percebam como criadoras, inventoras e investigadoras, tendo a possibilidade de interagirem de forma autônoma com o espaço, por meio da organização, planejamento e mediação do (a) professor (a).

Para tanto, a organização dos espaços, dos tempos e materiais em nosso fazer docente, leva em consideração todas as dimensões humanas 
potencializadas nas crianças: o imaginário, o lúdico, artístico, o afetivo e o cognitivo.

Nessa perspectiva de desenvolvimento das potencialidades é que o brincar consiste em um dos eixos norteadores do currículo de Educação Infantil, como apontam as Diretrizes Curriculares Nacionais para a Educação Infantil (DCNEls, 2009), pois é uma experiência que participa intensamente do processo de constituição da subjetividade da criança e de sua produção cultural. "Não há dúvida que brincar significa sempre libertação. Rodeadas por um mundo de gigantes, as crianças criam para si, brincando, o pequeno mundo próprio" (BENJAMIN, 2002, p. 85).

Então, pensamos, defendemos e acreditamos em uma Educação Infantil que sirva à infância, respeitando a criança em seu direito de brincar e, com isso, através de sua subjetividade, ela tem a oportunidade de recriar o mundo. E esse movimento nos leva a pensar nos recursos oferecidos para as crianças nos espaços e tempos da EMEI.

Dessa forma, as proposituras advindas da organização dos tempos, espaços e materiais a partir das Salas Temáticas precisam instigar as crianças a pensarem o mundo, a brincarem com possibilidades de ser e se fazer diferente, a brincarem com sua realidade e, a partir daí, criarem formas de se relacionarem com o outro, pois "[...] nada parece ser mais agradável, descompromissado e leve do que uma brincadeira com curiosidades". (BENJAMIN, 2002, p.138).

As Salas Temáticas possuem uma estrutura com materiais diversificados correspondentes a diversas linguagens e experiências diversificadas. Os materiais servem de subsídios para que a construção de conhecimento aconteça, cabendo aos (as) professores (as) a proposição de experiências significativas, a partir de um planejamento que conceba a criança como protagonista de suas vivências.

Assim, os espaços, os tempos e os materiais da EMEI são organizados levando-se em conta o objetivo da Educação Infantil de promover o desenvolvimento integral das crianças. Horn (2004) ajuda-nos a pensar sobre esse tema, afirmando que:

O olhar de um educador atento é sensível a todos os elementos que estão postos em uma sala de aula. O modo como organizamos materiais e móveis, e a forma como crianças e adultos ocupam esse espaço e como interagem com ele são reveladores de uma concepção pedagógica. Aliás, o que sempre chamou minha atenção foi a pobreza frequentemente encontrada nas salas de aula, nos materiais, nas cores, nos aromas; enfim, em tudo que pode povoar o 
espaço onde cotidianamente as crianças estão e como poderiam desenvolver-se nele e por meio dele se fosse mais bem organizado e mais rico em desafios. (HORN, 2004, p. 15).

Para a organização e manutenção das Salas Temáticas, faz-se necessária uma diversidade de materiais e suportes que favoreçam a criação e a criatividade das crianças, proporcionando vivências e experiências diversas, por meio das interações e brincadeiras, conforme preconizam os documentos mandatórios da Educação Infantil.

Nessa perspectiva, na Sala de Jogos utilizamos jogos diversos, como: quebra-cabeças variados, jogos da memória, sequência lógica, jogos de tabuleiros, bingos, dominós, jogos da velha, entre outros. São utilizados ainda, aramados e tangrans de diferentes formas, jogos de empilhar e encaixar, pecinhas de encaixe, tipo lego e de montar como fazenda, engenheiro, entre outros, além de materiais de amplas possibilidades, como tampinhas de diversas cores, formatos e tamanhos. Jogos de sequência de cores e números.

Nesta Sala, as experiências com a linguagem matemática, por meio de interações e brincadeiras que envolvem o raciocínio lógico, os números, a concentração e atenção, os jogos de regras, a orientação espaço temporal, a participação e autonomia, o desafio, fazem parte das proposituras deste espaço.

Para tanto, organizamos o espaço da Sala, assim como os externos, para que as crianças possam brincar e interagir com os jogos diversos que envolvem movimentos e regras, gincanas organizadas individualmente, em duplas, quartetos, grandes e/ou pequenos grupos, entre outras formas de organização, primando para que estes não sejam separados por "grupo dos meninos" e "grupo das meninas". Procuramos oferecer às crianças propostas que enriqueçam as experiências com a linguagem matemática, raciocino lógico-matemático, atenção e concentração.

Na Sala do Ateliê são disponibilizados recursos para as produções artísticas, como riscadores diversos: lápis de cor e escrever, caneta hidrocor, giz de cera fino e grosso, pinceis atômicos e de pelo, pinceis para quadro branco, giz em pó, canetas, tinta guache, massinha de modelar e argila. Papéis diversos, como sulfite, crepom, color set, cartolina, papel pardo, papel laminado, papel cartão, papelão, celofane, plástico, miçangas, lã, fitas, tecidos, serragem, aparas de lápis também fazem parte dos recursos. Este ambiente também conta com os materiais de amplas possibilidades, como tampinhas, rolos de papel, cones, CDs, elementos da natureza como folhas, 
galhos, areia, sementes, entre outros. Esta Sala favorece a expressão artística de forma não homogeneizante, ampliando o universo criativo e imaginário, trazendo à tona as emoções das crianças.

Assim, a Sala do Ateliê é organizada de forma que as crianças produzam individual ou coletivamente, desenhos, esculturas bi e tridimensionais, pinturas, colagens, recortes, utilizando materiais e suportes diversos, uma vez que quanto mais diversos são os materiais oferecidos, maiores e mais significativas são as experiências vivenciadas pelas crianças. A diversidade de materiais e suportes é apresentada em todas as propostas, para que assim as crianças, mediadas pelo (a) professor (a), se tornem protagonistas das suas criações.

Os elementos da natureza e os materiais não estruturados fazem parte do rol de materiais oferecidos às crianças. As propostas voltadas para a linguagem artística ocorrem dentro e fora da Sala. Na Sala do Ateliê, as crianças produzem elementos para as demais Salas, construindo jogos, instrumentos musicais, ilustração para histórias, entre outros. Nesta Sala, também são evidenciados a apreciação, o respeito e a valorização do fazer do outro. Os suportes para as produções artísticas do Ateliê vão muito além de uma folha $A 4$, pois as experiências das crianças não cabem neste espaço.

A Sala de Literatura conta com uma diversidade de portadores de textos como livros, revistas, gibis. Suportes para as produções de textos, tais como papéis para a confecção de cartazes e hipóteses de escrita das crianças, quadro branco, giz de bastão, lápis de escrever, pincel atômico e de quadro branco. Assim, buscamos favorecer o desenvolvimento das linguagens oral, escrita e teatral, a partir da organização do espaço onde as crianças tenham acesso a diferentes portadores de textos, podendo com eles e a partir deles construir hipóteses de escrita, compreendendo a função social da mesma, expressando-se por meio da interpretação das histórias, podendo ser oralmente, por meio da reescrita, do desenho ou da dramatização.

Nesta Sala, as crianças têm a oportunidade de produzir textos diversos e interpretar por meio de diferentes linguagens (oral, escrita, teatral), ampliando sua compreensão, uma vez que interpretar um texto vai além da decodificação das letras.

O encantamento pela leitura tem grande importância, faz com que a formação de leitores e leitoras seja um dos nossos objetivos. Em todas as Salas, diariamente, são realizadas leituras, porém, na Sala de Literatura, as propostas e o fazer pedagógico são permeados principalmente pela contação de histórias. Neste espaço, são utilizados diversos materiais disponíveis 
e estratégias para esses momentos de fantasia e imaginação: leituras, dramatização com fantoches, dedoches, caixa mágica, quadro de feltro, avental, fantasias diversas, entre outras possibilidades. Nesse ambiente, as crianças se percebem ativas nesse processo, ouvindo e contando histórias, sendo protagonistas das suas próprias vivências.

Para a Sala de Ciências e Tecnologia, são disponibilizados equipamentos tecnológicos como computadores, materiais para medidas - régua, pesos, medidores de líquidos, colheres, recipientes diversos, mapas, dorso humano, sequência lógica do nascimento de animais e plantas e da produção dos alimentos, garrafas PET, caixa de insetos, lupas e microscópio. Materiais de amplas possibilidades: canudos, pipetas, suportes para os registros das observações: papéis, lápis, pincel atômico, marcador de quadro branco também compõem este espaço de aprendizagem.

Com isso, buscamos incentivar a curiosidade e o levantamento de hipóteses, sendo o uso das tecnologias considerado como um desafio a ser encarado, principalmente, nesta Sala, uma vez que as crianças, de maneira geral, têm acesso às tecnologias, então cabe à escola, planejar formas de ampliar seus conhecimentos diante desses recursos.

As experiências relacionadas ao mundo físico e natural ganham destaque nessa Sala. A partir dos elementos da natureza é possível oferecer experiências para as crianças de modo que possam criar hipóteses, sintetizar processos complexos, misturar e criar elementos, entre outras diversidades de possibilidades.

A Sala de Música e Movimento é composta por equipamentos de áudio e vídeo (caixa amplificadora de som e data show), bandinha, músicas diversas, materiais não estruturados e de amplas possibilidades, sucatas, latas e materiais diversos para encher potes, tipo pedras, sementes, areia.

Dessa forma, evidenciamos tanto a linguagem musical como a corporal, organizando-as de modo que as crianças possam fazer música partindo da compreensão do som e do silêncio e, a partir daí, usarem diversos materiais para a criação, como: com o corpo, com a bandinha, com os materiais não estruturados, com as sucatas.

Esta Sala também é voltada para a apreciação musical, onde as crianças têm acesso a um repertório musical amplo, ouvindo diversos gêneros musicais, uma vez que a criança fala com o corpo. Assim, compreendemos que nenhuma Sala deve aprisionar os corpos das crianças, porém, neste espaço, o movimento é rítmico e coreografado, a criança interpreta a partir do movimento do corpo. Vale destacar que nem o movimento nem a músi- 
ca ficam restritos nesta Sala, a criança movimenta-se de diferentes formas por toda a instituição.

Já na Brinquedoteca, temos brinquedos diversos, bonecas, carrinhos, panelinhas, pelúcias, dinossauros, kits de médicos, engenheiros, ferramentas, teclados e telefones, peças de madeira, espumas de macarrão de piscinas, canos e conexões, tecidos, roupas para as bonecas, mobiliário de casinha, casinha de MDF, onde as crianças entram para realizar suas brincadeiras, entre outras propostas. Neste espaço, também são utilizados elementos da natureza e os materiais não estruturados de largo alcance para ampliar as possibilidades para o faz de conta.

A Brinquedoteca é a preferida pelas crianças, segundo relatos destas, pois nesta Sala busca-se privilegiar a linguagem corporal e a imaginação, possibilitando que a criança brinque de faz de conta, utilizando-se de diferentes suportes para enriquecer esses momentos. Nas suas brincadeiras e formas de usar os brinquedos, interpretam e questionam o mundo. Neste fazer das crianças, os (as) professores (as) observam de que e com quem a criança brinca, como parte da observação intencional do fazer pedagógico.

A Brinquedoteca possibilita a compreensão dos anseios e desejos das crianças, pois é um espaço organizado para o brincar de faz de conta, onde a criança se mostra e, dessa forma, precisamos olhá-la e vê-la em sua inteireza. Neste ambiente, o faz de conta é propiciado com os brinquedos industrializados, com as sucatas e com materiais de amplas possibilidades, além do diálogo constante com as crianças, a partir do momento que elas permitem que o adulto brinque e compartilhe com elas esse mundo da imaginação.

Com essas seis Salas Temáticas e os demais espaços externos da Unidade, a definição de uma metodologia de trabalho que atenda às especificidades das crianças e das infâncias da Educação Infantil configura-se como um imenso desafio. Desse modo, para que este projeto continue com eficiência e de fato possibilite experiências significativas para as crianças, todo ano letivo, alguns pontos precisam ser levados em consideração.

Ao nos apoiarmos na Sociologia da Infância ${ }^{2}$, a escuta atenta a partir de uma relação dialógica entre criança e adulto precisa fazer parte do co-

\footnotetext{
${ }^{2}$ Conforme aponta Corsaro (2011), os conceitos da Sociologia da Infância se vinculam no reconhecimento da criança como protagonista de suas vivências, como sujeito que tem voz, que atua socialmente, compreendendo suas experiências a partir de um ponto de vista pró prio sobre o mundo em que vive, pertencente a uma categoria geracional própria: a infância. A partir da Sociologia da Infância, autores como Anete Abtamowicz, Ana Lúcia Goulart de Faria, Willian Corsaro, Manuel Sarmento concebem a criança partindo de um olhar de completude e não mais como um vir-a-ser.
} 
tidiano da instituição, para além de escutar torna-se necessário uma observação aguçada nas particularidades expressivas das crianças. Quais seus desejos e anseios? Quem são as crianças da EMEl? Quais as culturas infantis que compõem a EMEI? Essas são questões orientadoras que norteiam a organização do nosso fazer pedagógico para e com as crianças.

A criança é a protagonista neste processo, mas nós que somos professores (as), temos um grande papel, somos nós quem temos que ter uma observação intencional, minuciosa e propormos as experiências para as crianças. Dessa forma, as rodas de conversa, os momentos de debate e as assembleias, tornam-se de grande importância, uma vez que essas são estratégias para pensar, a partir e com as crianças a organização dos tempos, espaços e materiais.

Para tanto, as seis Salas temáticas da EMEI não são compreendidas como espaços estanques, finitos, mas de amplas possibilidades, já que uma Sala Temática não pode ter um objetivo único para uma única linguagem, ao contrário, as Salas abrem um leque de possibilidades de inter-relações das diferentes linguagens dentro dos temas propostos pelos projetos semestrais que também partem da escuta das crianças.

\section{Nosso caminho é feito de encontros e reencontros}

Até o momento, o desejo é o de que esta organização da Escola em Salas Temáticas seja efetivada nos próximos anos, por isso a avaliação final ganha status de culminância, uma vez que, a partir dela, é possível projetar novos caminhos para os próximos anos, observando quais as fragilidades precisam ser superadas e quais propostas ampliadas.

O acompanhamento do envolvimento, da construção de conhecimentos e experiências das crianças é registrado por meio de fotos e caderno de campo para, posteriormente, contribuir na elaboração do relatório semestral de desenvolvimento integral das crianças, além de servir de base para planejamentos e avaliações.

Nos momentos de planejamento, durante a Hora de Trabalho Pedagógico (HTP), são avaliadas as propostas apresentadas em cada Sala Temática e, a partir de então, planejadas novas proposituras. Nas Horas de TrabaIho Pedagógico Coletivo (HTPCs), realizamos estudos com vista a suprir as necessidades apontadas nos planejamentos.

Além disso, a escuta da comunidade escolar no dia a dia, no decorrer do ano, faz parte da avaliação desse projeto e seus anseios contribuem para que as Salas Temáticas sejam melhoradas, aprimoradas. 
No final do segundo semestre, é realizada avaliação com os (as) funcionários (as) e a comunidade escolar para levantar os pontos positivos e negativos desta organização para preparar o próximo ano letivo.

Assim, ao longo de cada ano a ambientação tem acontecido de forma tranquila, e os familiares mostram-se animados com a possibilidade de verem as crianças participando de diferentes propostas. Com isso, a cada dia, temos a clareza de que não existe um manual para as crianças, elas são únicas e o que precisamos fazer é respeitar a individualidade e o tempo de cada uma. Desse modo, a ambientação acontece de forma mais tranquila e agradável.

Portanto, para que esse processo aconteça de forma prazerosa para todos, especialmente para as crianças, é necessário um respeito grande a cada especificidade, como também uma parceria com a família, a qual aceita o desafio de propor algo novo para a criança.

Enfim, olhar, pensar e respeitar a criança numa perspectiva cidadã significa entendê-la em suas especificidades e singularidades, ao mesmo tempo em que ela é reconhecida como sujeito coletivo, social, merecedora de igualdade de direitos e respeito, inerentes à verdadeira cidadania. Diante disso, acreditamos que essa proposta pedagógica da EMEI, para que possa continuar proporcionando essa construção, precisa ser entendida que:

[...] um caminho, não é um lugar. Uma proposta pedagógica é construída no caminho, no caminhar. Toda proposta pedagógica tem uma história que precisa ser contada. Toda proposta pedagógica possui uma aposta. Nasce de uma realidade que pergunta e é também busca de uma resposta. Toda proposta é situada, traz consigo o lugar de onde fala e a gama de valores que a constitui; traz também as dificuldades que enfrenta, os problemas que precisam ser superados e a direção que a orienta. E essa sua fala é a fala do desejo, de uma vontade eminentemente política no caso de uma proposta educativa, e sempre humana, vontade que, por ser social e humana, não é nunca uma fala acabada, não aponta o lugar, a resposta, pois, se traz a resposta, já não é uma pergunta. Aponta, isso sim, um caminho também a construir. (KRAMER, 1999. p. 169)

O projeto das Salas Temáticas é um caminho que estamos trilhando, na certeza de que é necessário o envolvimento do coletivo neste processo, respeitando as crianças e suas infâncias, através, principalmente, de uma avaliação contínua que observa, registra e planeja novas ações, uma avaliação que seja dinâmica, viva e não deixe o projeto ficar parado. E as- 
sim, vamos caminhando e construindo novos horizontes para a educação da criança pequena.

\section{Referências}

BENJAMIN, Walter. Reflexões sobre a criança, o brinquedo e a educação. São Paulo: Duas Cidades; Ed. 34, 2002.

BRASIL. Secretaria de Educação Básica. Diretrizes Curriculares Nacionais para a Educação Infantil. Brasília: MEC, SEB, 2010.

CORSARO, W. A. Sociologia da Infância. 2. Ed. Porto Alegre: Artmed, 2011.

HORN, Maria da Graça. Cores, Sons, Aromas e Sabores: A Organização do Espaço na Educação Infantil. Porto Alegre: Artmed, 2004.

KRAMER, Sônia. Propostas Pedagógicas ou Curriculares: subsídios para uma leitura crítica. In: MOREIRA, Antônio Flávio Barbosa (orgs.). Currículo: políticas e práticas. Campinas, SP: Papirus, 1999.

MALAGUZZI, Loris. História, ideias e filosofia básica. In: EDWARDS, C.; GANDINI, L.; FORMAN, G. As cem linguagens da criança. Porto Alegre: Artmed, 1999. p. 59-104. 